\title{
To TxT or Not to TxT: That's the Puzzle
}

\author{
Tiong-Thye Goh and Val Hooper \\ School of Information Management, \\ Victoria University of Wellington, Wellington, New Zealand
}

\author{
tiong.goh@vuw.ac.nz; val.hooper@vuw.ac.nz
}

\section{Executive Summary}

This paper describes the potential use of a mobile phone Short Message Service (SMS) crossword puzzle system to promote interaction through learning activities in a large classroom environment. While personal response systems (PRS) have been used in the classroom environment to foster interaction, it is not an ideal tool with respect to cost and functionality. These limitations prompted the need for an alternative solution.

An SMS crossword puzzle system was thus devised. The system consists of two parts: modem software to interface with mobile phones and a database application to generate puzzles, track users' input, and display an updated puzzle view. A pilot evaluation was conducted with three main objectives in mind. Firstly, the evaluation intended to determine the motivational potential of the puzzle by assessing the significance of the factors that comprise the constructs of learner motivation. Secondly, the evaluation intended to identify any differences in motivational factors between a first and a third year class. Finally, the evaluation intended to assess the potential of behavioral intention to use/play the SMS crossword puzzle in the future. The pilot evaluation also sought to identify areas for improvement and to prepare for future full scale evaluation of the SMS crossword puzzle system.

The SMS crossword puzzle was used in two undergraduate information systems classes: a first year foundation course class and a third year elective course class. Each class had a separate puzzle to play with a different set of clues. In the subsequent evaluation, participants of Group 1 consist of 10 students from the first year class, and participants of Group 2 consist of 15 students from the third year class.

The instrument used in the evaluation was a survey adopted from Keller's (1987) studies on motivation theory. Using a 5-point Likert scale, the items covered the motivation factors of attention, relevance, confidence and satisfaction. A single item construct was used to assess the behavioral intention to use.

The findings show that students from the first year class found the SMS crossword puzzle much

Material published as part of this publication, either on-line or in print, is copyrighted by the Informing Science Institute. Permission to make digital or paper copy of part or all of these works for personal or classroom use is granted without fee provided that the copies are not made or distributed for profit or commercial advantage AND that copies 1) bear this notice in full and 2) give the full citation on the first page. It is permissible to abstract these works so long as credit is given. To copy in all other cases or to republish or to post on a server or to redistribute to lists requires specific permission and payment of a fee. Contact Publisher@InformingScience.org to request redistribution permission. more interesting (attention factor) than students from the third year class, while the third year class found the puzzle neither easy nor difficult to play (confidence factor). With regard to the other components of the motivational factors, no significant difference between the two groups was found. Overall the mean scores were significantly above the mean scale score $(>3)$. 
Both groups showed significant interest in playing the game in the future, signaling the possibility of adoption. The evaluation also identified SMS latency as being an issue in deploying SMS for near real-time interactive activities. However, the issue can be resolved with distributed architecture and collaboration with a telecom operator or by deploying normalizing strategies to overcome the bottleneck. Finally, the SMS crossword puzzle should be treated as part of a unified service of deploying SMS technology in an educational environment for services such as voting, quizzes, discussion forums, notification of due dates of assignments, examination results, and library services.

Keywords: short message service (SMS); mobile phones; interactive learning; crossword puzzle

\section{Introduction}

Promoting classroom interaction has been shown to enhance learning (Anderson, 2002; Markett, Sánchez, Weber, \& Tangney, 2006). However, encouraging participation and deploying learning activities in large classes that range in size from 100 to 200 students can be very challenging. One way in which the problem can be overcome is by the use of information and communications technology (ICT).

An emerging ICT that can be deployed to engage students is the audience response system (ARS), or personal response system (PRS). Positive learning experience has been reported through the use of ARSs (Eggert, West \& Thomas, 2004). The ARS uses wireless keypad technology, also known as clicker technology, for real-time communication with a server. However, one issue with wireless keypad, or clicker, technology is that it may have a restricted duration license. Often the license to use the system is limited to a single semester (Purdue, 2006) and a new license must be purchased for use to continue. Updating the license is normally done through the purchase of a new code. Frequently this is also tied to textbook purchase (OSU, 2006). Another limitation of clicker technology is that it has restricted functionality; it cannot provide responses that require text entry. Normally an ARS only uses multiple choice questions with a projector screen. The adoption of clicker technology as an ARS for classroom interaction, though very useful, is thus not ideal. There is consequently a need to look beyond clicker technology to achieve classroom interaction. The solution should provide an interesting and motivational medium to promote learning and interaction, while at the same time it should minimize the need for students to purchase hardware.

One of the most omnipresent gadgets carried by university students nowadays is the mobile phone. Mobile phones seem to have become the most popular communication devices for the current Y generation, irrespective of country or culture. For example, in China the latest statistics from the Ministry of Information Industry (MII) show that the short message service (SMS) of mobile phones in China hit an historical record in the first quarter of 2006 with the daily average number of SMS messages sent reaching 1.098 billion (China SMS, 2006).

Therefore, the idea of adopting the use of the mobile phone with SMS capability as a PRS presented an appealing and practical option to be explored.

\section{Objectives of the Study}

With this in mind, the objectives of this study were, firstly, to explore the feasibility of using the SMS facility of mobile phones to promote learning through the use of an SMS crossword puzzle activity in a classroom environment. The second objective was to examine the motivational capacity of using a mobile phone - specifically for an SMS crossword puzzle - for learning purposes. The third objective, which is related to the second objective, was to explore the potential adoption of such a system as an educational tool by students. Simply, the objectives aim to under- 
stand whether, if a system is developed, users (students) will use it and what factors will motivate them to do so.

This paper thus initially provides an overview of the relevant literature. Firstly, the use of SMS in education is explored, then the motivation aspect of games in the context of learning, and finally, the SMS technology. The next section describes an SMS crossword system that was based on the literature and was developed to promote learning activity in the classroom. The last two sections provide more detail of the implementation and evaluation of the SMS crossword system with respect to the stated objectives.

\section{Background Literature}

\section{SMS in Education}

The adoption of SMS as an educational tool has recently become popular in education. For example, Lian (2003) developed an innovative teaching strategy that effectively integrates SMS technology into the teaching and learning process. Lian's approach uses two feedback loops established between the learners and the educator. The first loop is the in-class feedback using an SMS message based on a quiz system. The second loop is the after-class feedback realized by an educator-to-learner portal, the e-learning hub. In addition, the adaptive technique is deployed to trace the learners' performance during and after a lecture. According to Lian the benefit of the system is that through the adaptive technique, the lecturer can quickly adjust the course content to suit the needs of the learners. This type of benefit is difficult to achieve through a more traditional audience response system such as clicker technology, which is typically a simplex communication tool. However, adoption and experience from the students' perspectives were not reported in Lian's (2003) study. It is not clear whether this approach was, or would be, adopted by the students, and what the motivational factors were that would sustain the use of SMS in the classroom. The current research intends to examine these issues.

The "PLS TXT UR Thoughts" (Markett et al., 2006) project, which is similar to Lian's (2003) project, involved students initiating interactivity in class using SMS. The aim of the project was to encourage interaction in the classroom (Markett et al., 2006). Interaction was through the text messages sent by the students. Once these messages were received, the lecturer could view the messages and verbally provide feedback to students during the class. One useful feature of the system is that the SMS messages are available online after class, allowing interactive loops to develop further via threaded comments (Markett et al., 2006). It is almost impossible for clicker technology to match the capability of an SMS system in this instance. However, according to the research, $33 \%$ of the students indicated that focusing on mobile phones to send text messages while simultaneously trying to listen to a lecture was distracting.

This strengthened the belief that in order to promote interactivity in the classroom using SMS, a more streamlined approach in adopting relevant pedagogy would be necessary. A more suitable approach would be to allocate a specific time for SMS interaction activity rather than having SMS interaction throughout the entire lesson.

In addition to the above examples, a large number of researchers have adopted SMS technology for learning in a variety of innovative ways. Bollen, Eimler and Hoppe (2004) used SMS for inclass discussion in a way which was similar to Lian (2003) and Markett et al. (2006). Howie (2004) reported the use of SMS to allow pupils to do homework using their phones to download the information on the subject. Stone, Briggs, and Smith (2002) suggested the use of SMS in a complex learning "journey" where a series of interactive SMS exchanges lead to completion of a task or achievement of a goal. Houser and Thornton (2004) used SMS for learning language vo- 
cabulary, and for study support. SMS has also been deployed as a tool to communicate with students and parents about day-to-day college information, such as timetable details, assignment due dates, parent evenings and college events (Derby, 2003). Most of these examples reported a positive influence on students' learning and acceptance of the technology provided that the medium is used towards educational advantage. These examples demonstrate the extensibility of SMS technology that goes beyond what an ARS, such as clicker technology, can offer.

While these examples illustrate the various modes of using SMS, the deployment of SMS games as a fun and motivational learning tool has not been reported widely. Also apparently lacking is the understanding of the motivational characteristics of using SMS for classroom learning.

With this in mind, the current research aims to complement the educational research in the SMS by investigating the motivational characteristics of using SMS games for learning from students' perspective. The background to educational motivation, and particularly with regard to games, is thus examined.

\section{Motivation and Games}

According to Prensky (2003), "A sine qua non of successful learning is motivation: a motivated learner can't be stopped." Motivation is a key factor in achieving a successful learning outcome. It is not uncommon to watch self-motivated children playing video games at home or in arcades with intense energy and enthusiasm. Thus one approach that could provide motivation for the learner is to use the strategy of "gameplay" in an education environment (Prensky, 2002). From an educational perspective, digital games have become widely accepted as a potentially important source of education and learning because of their ability to motivate and engage the learner (Galarneau, 2005; Kearney, 2005; Medina, 2005). While SMS technology has been used in the educational environment, the motivational aspect of SMS games as a learning tool is however not fully understood. It was with this objective in mind, we set out to evaluate the motivational capacity of the SMS crossword game.

There are many motivational theories in educational psychology. They can generally be divided into three main groups: the behavioural theories that focus on reward or deprivation, as well as reinforcement; the cognitive theories that include the attributional theories and equilibriumseeking motivation; and the humanistic theories that emphasize the need for achievement and gratification (Song \& Keller, 2001). There are two models, nevertheless, that do present holistic approaches to motivational design. Both have been widely used, validated and cited. They are the ARCS model of Keller (1987a, 1987b, 1987c) and Wlodkowski's (1999) time-continuum model.

The ARCS model represents four categories of motivational factors. They are attention, relevance, confidence and satisfaction. These categories were formed from the aggregation of many theories and were based on the various attributes and discriminative attributes of each. Grounded in the general theory of motivation and performance, the dependent variables of the model are effectiveness and perceived motivation, as well as efficiency and continuing motivation (Keller, 1987a, 1987b, 1987c). The ARCS model has been particularly useful to instructional designers because it facilitates a clear understanding of motivation in terms of the four categories. It also provides clear motivational strategies and tactics, as well as a systematic approach to the motivational design and evaluation process (Song \& Keller, 2001).

Wlodkowski's (1999) model, on the other hand, adopts a time-oriented approach in which a number of motivational strategies are provided along with the prescription of when each of them should be used. This covers the complete duration of an educational episode. It is far more prescriptive than the ARCS model and provides neither the systematic strategy selection options of the ARCS model nor the emphasis on a problem-solving approach. 
For the purposes of this research, the ARCS model provides a more suitable theoretical basis and is adopted for the evaluation.

\section{SMS Technology}

SMS is a wireless service for sending text messages to mobile phones that are supported by a Global System for Mobile (GSM) communication and a Code Division Multiple Access (CDMA) mobile network. Each message can hold up to 160 characters including alphanumeric or binary non-text short messages. SMS supports both national and international roaming. This feature is very useful for non-face-to-face interaction. This thus extends the possibility for distance learning students to engage in interaction. In contrast, clicker technology is localized, and it is not possible to extend it to non-face-to-face distance learning students.

SMS works on a store-and-forward basis. If the recipient's phone is turned off, they will be able to receive the text message when it is turned on (Tung, 2004). Currently there are different ways of sending and receiving SMS text messages. A message can be sent or received via the network operator's message center to a mobile phone, or from the Internet, using the SMS gateway website (Tung, 2004). This aspect is useful for multi-channel interaction where students can use a laptop to interact with a mobile phone. Incorporating these extra features of SMS as a PRS widens the potential application and scope of the system as compared to the limited features of clicker technology which is typically one-way communication. Utilizing SMS for classroom interaction thus extends the role of a mobile phone and enhances the potential usefulness of such a device.

With respect to interaction and learning, SMS has some limitations. Firstly, for a standard phone each message can be up to only 160 characters long or 70 characters if 16-bit Unicode UCS2 character encoding is used, such as with Chinese characters. Therefore the length of query content to be sent is limited, as is the amount of feedback to be received (unless the message is broken into multi-segments). Secondly, SMS uses a slow signaling channel, typically Signal System 7 (SS7), so it experiences low data rates and latency. Latency creates a time gap between the message being sent and the message being received. SMS delivery is a best effort technique, so there are no guarantees that a message will actually be delivered to its recipient, and delay or complete loss of a message is not uncommon, especially when sending between operators (Geek, 2006). Latency ranging from 30 seconds to 60 seconds is not uncommon (Geek, 2006). The delay can be an influential factor for instant interactivity in a classroom. The latency can be worse if many students simultaneously send an SMS message within a lecture theater if the short message service center (SMSC) does not have sufficient capacity and utilizes centralized message architecture. Thirdly, inevitably cost might hinder the usage of SMS as an interactive tool. However, compared to the purchase of a clicker technology, current SMS plans can be very affordable. With reverse charging and bulk purchase of text messages, for example Clickatell ${ }^{\mathrm{TM}}$ (Clickatell, 2007); the cost issue can be minimized both for students and the institution.

Thus, in-class learning activities using SMS must take account of these factors in the design of the planned activity and teaching delivery.

\section{Research Design}

Based on the literature review, it appeared that in order for the SMS technology to be successfully employed as a learning tool it needs to be motivational, engaging, fun, and to be continuously challenging at different educational levels (Prensky, 2002). It should also have the potential to be used in a group manner. An SMS crossword system was thus devised which aimed to fulfill these 
requirements and provide a test bed for validating these requirements. This paper focuses on the motivational aspect of such an SMS crossword game.

\section{The SMS Crossword Puzzle}

The SMS crossword puzzle consists of several pieces of software and hardware as shown in Figure 1. These include the SMS software, a mobile phone plus cable or data card, a laptop computer, and a database. The SMS software is basically modem communication software. It resides in the laptop and communicates with the SIM card of the mobile phone that is attached to the laptop. The SMS crossword puzzle is similar to playing a paper based crossword puzzle except that the user needs to send the word with the corresponding direction and number through an SMS message. For example if a user needs to send the word "VIRUS" in answer to the clue for 6 down, then he sends the text message as "D6 VIRUS". Once a message is received from the mobile phone, the SMS software checks the incoming message and transfers the message and caller information to the database. The algorithm analyzes the message. If the message is correct, it will update the puzzle and the database table. If the message is incorrect, it will only store the message for future analysis. The backend database software also contains the algorithm for generating the puzzle template, the scoring and the display system. During the game, the puzzle is displayed on the projector screen. Students see the first correct response immediately on the screen, together with the last 5 digits of the mobile phone number of the sender (see Figure 2). This creates a realistic, involving, and exciting experience for the students.

Through the use of the SMS crossword puzzle, learning content with various degrees of difficulty can be tailored for different class levels. Questions can be created as clues to the puzzle. A group of students can work together to solve the puzzle if group learning is desired. Students can also send individual queries to be captured in the database for in-class question and answer sessions. The lecturer, or educator, can extract the information and easily build up a knowledge base for future reference.

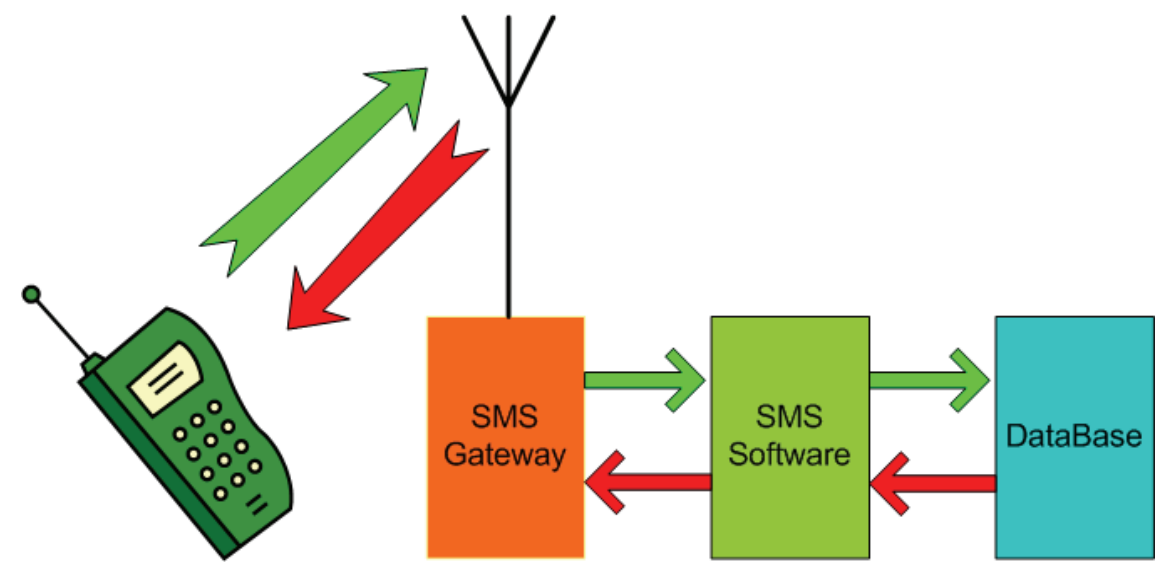

Figure 1: Software and hardware of SMS puzzle 


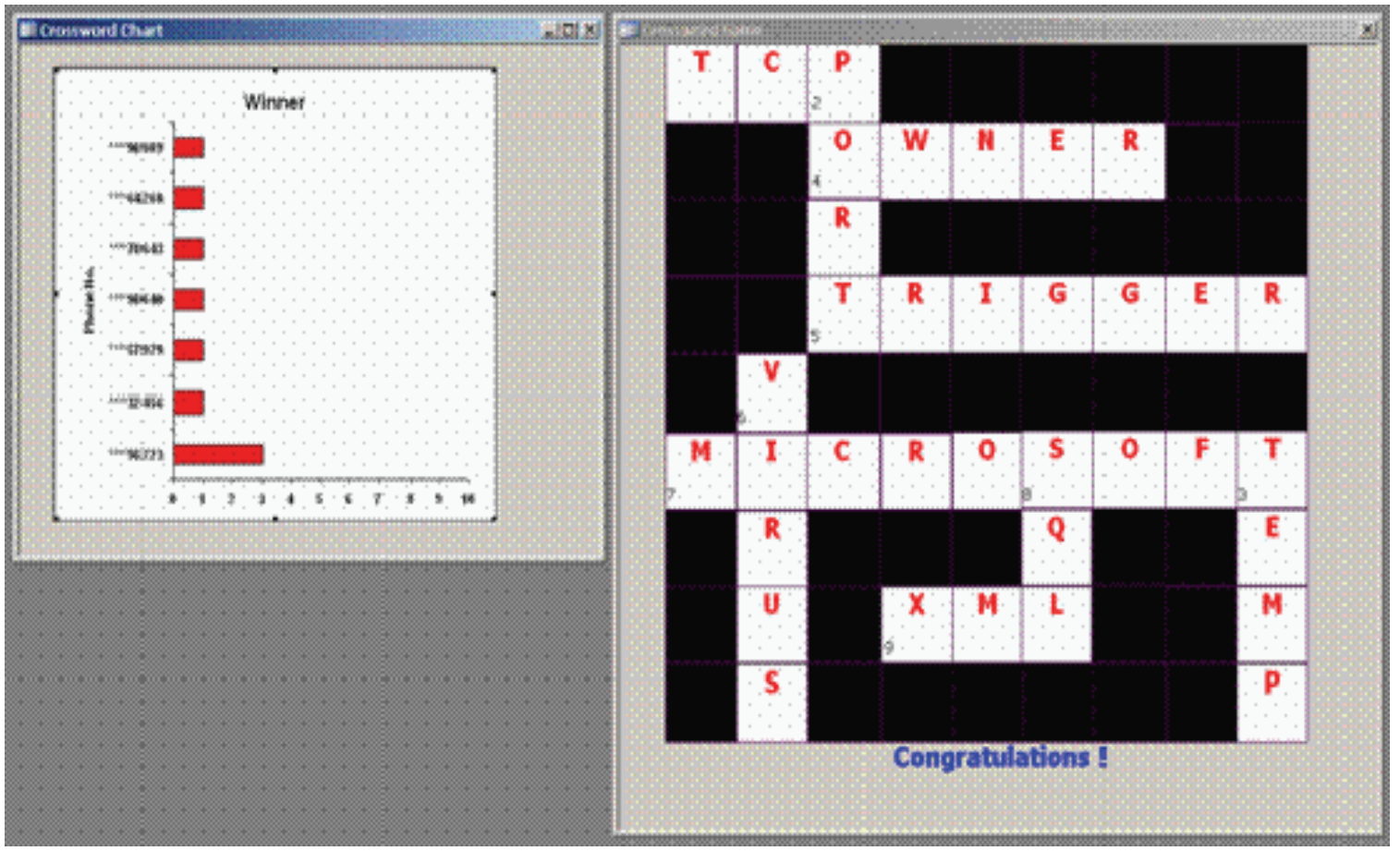

Figure 2: Completed crossword as displayed on the projector screen

\section{Evaluation of the SMS Crossword Puzzle System}

In order to assess the impact of the system, as well as any differences that might exist between different levels of students, the evaluation was conducted in two different classes. The first evaluation involved a first year information systems class. The second evaluation involved a third year database and programming class.

In the first year class, the lecturer first spent 35 minutes presenting the lecture material to be covered in the game. The game was then explained to the class and students were directed to organize themselves into teams of about three students each. The lecturer then distributed a puzzle sheet, which contained the clues, to each student. Once everyone had received a sheet of clues, the phone number was given which the team representative had to dial and to which the answer had to be sent. The respondent with the first correct answer was the winner for that question, and the respondent with the most correct answers was the overall winner.

The procedure of the third year class was similar to that of the first year class. The only difference in the process was that in the third year class, the puzzle sheet was given to each student before the lecture presentation. Students in the third year class would thus have had more time to solve the puzzle than the first year students.

\section{Evaluation objectives}

The purpose of the evaluation was to provide an indication of answers to three main questions:

(a) What is the significance of the different motivational factors in participating in the SMS crossword puzzle as an in-class learning tool?

(b) Are there any differences in the level of motivational factors between the first year and third year students? 
(c) What is the level of potential adoption of such a system?

\section{Survey instrument}

The instrument for the evaluation was constructed according to a short version of Keller's ARCS motivational factors of Attention, Relevance, Confidence and Satisfaction (Keller, 1987a, 1987b, 1987c; Dempsey, Lucassen, Haynes, \& Casey, 1997). A full version of the instrument consists of 36 items and can be found in Dempsey et al. (1997). The current instrument uses a modified subset of the 36 items. The factor, Attention, consists of Perception Arousal (Q1), Inquiry Arousal (Q2), and Variability (Q3). The factor, Relevance, consists of Goal Orientation (Q4), Motive Matching (Q5), and Familiarity (Q6). The factor, Confidence, consists of Learning Requirement (Q7), Success Opportunity (Q8), and Personal Control (Q9). The final factor, Satisfaction, consists of Natural Consequence (Q10), Positive Consequence (Q11), and Equity (Q12). The last item (Q13) is to assess the Intention of future use. The instrument uses a five-point Likert scale. The ' 5 ' represents strongly agree, '4' agree, ' 3 ' neutral, '2' disagree, while ' 1 ' represents strongly disagree and 'NA' represents not applicable.

After the implementation of the puzzle, evaluation surveys were conducted. Participation was voluntary. According to the log files, about fifty students actually sent SMS but in total ten students from the first year submitted the evaluation form, and fifteen students from the third year. While this was a small proportion of the two classes, as the study was still very much in its exploratory phase, this was deemed sufficient at this stage of development.

\section{Findings}

The findings from the ten students from the first year class (Group 1) are depicted in Table 1. It shows that participants found the SMS crossword puzzle very interesting (Q1: 4.7, Q2: 4.5), satisfying (Q11: 4.1), and fair (Q12: 4). They didn't find it boring (Q3:2.2) nor did they find it difficult to play (Q8:1.9). With respect to the personal control aspect, most students seemed noncommittal about playing as a group or individually (Q9:3). However, most students expressed a keen desire to play the game again (Q13:4.2). Overall the mean motivation score for the first year class was 3.75 out of 5 .

The findings from the 15 students from the third year class (Group 2) are also depicted in Table 1. It shows that participants found the SMS crossword puzzle to be less interesting (Q1:3.7, Q2:3.8), less satisfying (Q11:3.8), and less fair (Q12:3.6) compared to the first year class. The third year students also found it just slightly boring (Q3:3.1) and nether easy or difficult to play (Q8: 3). With respect to personal control, like the first year group, most students were non-committal about playing individually or as a group (Q9:3). The third year students also expressed interest in playing the game again (Q13: 3.7). Overall the mean motivation score for the third year class was 3.5 out of 5 which was only slightly lower than that of the first year class. 
Table 1: Comparison of survey results

\begin{tabular}{|c|c|c|c|c|c|c|}
\hline & Survey Questions & $\begin{array}{l}\text { Motivational } \\
\text { factors }\end{array}$ & $\begin{array}{l}\text { Group } \\
1 \\
\text { Mean } \\
\text { score }\end{array}$ & $\begin{array}{l}\text { Group } \\
2 \\
\text { Mean } \\
\text { score }\end{array}$ & $\begin{array}{l}\text { Significant } \\
\text { Difference } \\
\text { of Mean } \\
\text { score } \\
\end{array}$ & $\begin{array}{l}\text { Significant of } \\
\text { Mean score } \\
(\text { Group } 1+2)>3\end{array}$ \\
\hline 1 & $\begin{array}{l}\text { The SMS Crossword puzzle presented } \\
\text { to me was interesting. }\end{array}$ & $\begin{array}{l}\text { Perceptual } \\
\text { arousal }\end{array}$ & 4.7 & 3.7 & $0.012^{*}$ & $0.000^{*}$ \\
\hline 2 & $\begin{array}{l}\text { The SMS Crossword puzzle had ele- } \\
\text { ments that raised my curiosity. }\end{array}$ & $\begin{array}{l}\text { Inquiry } \\
\text { arousal }\end{array}$ & 4.5 & 3.8 & 0.052 & $0.000^{*}$ \\
\hline 3 & $\begin{array}{l}\text { The repetitive nature of the SMS } \\
\text { Crossword puzzle caused me to be } \\
\text { bored. }\end{array}$ & Variability & 2.2 & 2.9 & 0.085 & 0.107 \\
\hline 4 & $\begin{array}{l}\text { It was clear to me from the beginning } \\
\text { what the goals of the SMS Crossword } \\
\text { puzzle game were. }\end{array}$ & $\begin{array}{l}\text { Goal } \\
\text { orientation }\end{array}$ & 3.1 & 3.7 & 0.211 & $0.038^{*}$ \\
\hline 5 & $\begin{array}{l}\text { The SMS Crossword puzzle is rele- } \\
\text { vant to my learning. }\end{array}$ & $\begin{array}{l}\text { Motive } \\
\text { matching }\end{array}$ & 3.5 & 3.8 & 0.373 & $0.001^{*}$ \\
\hline 6 & $\begin{array}{l}\text { The SMS Crossword puzzle is differ- } \\
\text { ent from my learning interest and } \\
\text { background. }\end{array}$ & Familiarity & 3.0 & 3.3 & 0.478 & 0.346 \\
\hline 7 & $\begin{array}{l}\text { After hearing the instructions, I was } \\
\text { sure what the objectives of the SMS } \\
\text { Crossword puzzle were. }\end{array}$ & $\begin{array}{l}\text { Learning } \\
\text { requirements }\end{array}$ & 3.5 & 3.7 & 0.578 & $0.003^{*}$ \\
\hline 8 & $\begin{array}{l}\text { The SMS Crossword puzzle game was } \\
\text { difficult for me to play. }\end{array}$ & $\begin{array}{l}\text { Success } \\
\text { opportunity }\end{array}$ & 1.9 & 3.0 & $0.034^{*}$ & 0.135 \\
\hline 9 & $\begin{array}{l}\text { Completing the SMS Crossword puz- } \\
\text { zle requires a group effort }\end{array}$ & $\begin{array}{l}\text { Personal } \\
\text { control }\end{array}$ & 3.0 & 3.1 & 0.864 & 0.840 \\
\hline 10 & $\begin{array}{l}\text { I think I acquired some knowledge } \\
\text { from doing the SMS Crossword puz- } \\
\text { zle that I might be able to use in an- } \\
\text { other aspect of my learning. }\end{array}$ & $\begin{array}{c}\text { Natural } \\
\text { consequences }\end{array}$ & 3.7 & 3.6 & 0.849 & $0.000^{*}$ \\
\hline 11 & $\begin{array}{l}\text { Completing the SMS Crossword puz- } \\
\text { zle gave me a satisfying feeling of } \\
\text { accomplishment. }\end{array}$ & $\begin{array}{c}\text { Positive } \\
\text { consequences }\end{array}$ & 4.1 & 3.8 & 0.342 & $0.000^{*}$ \\
\hline 12 & $\begin{array}{l}\text { The SMS Crossword puzzle is a fair } \\
\text { game, given my knowledge of INFO } \\
101 .\end{array}$ & Equity & 4.0 & 3.6 & 0.408 & $0.001^{*}$ \\
\hline 13 & $\begin{array}{l}\text { I would play the SMS Crossword } \\
\text { puzzle game again. }\end{array}$ & $\begin{array}{l}\text { Behavioural } \\
\text { intention }\end{array}$ & 4.2 & 3.7 & 0.267 & $0.000^{*}$ \\
\hline
\end{tabular}

*significant at $\mathbf{P}<\mathbf{0 . 0 5}$ 
Compared with the first year class, the third year class was better able to comprehend the goal and objective of the game (Q4: 3.7, Q7: 3.7) and also found the game relevant to their learning (Q5: 3.8). However the third year class believed that the game was slightly different from their interest and background (Q6:3.3). By computing a t-test between the two groups, only Q1 and Q8 demonstrated a significant difference at a $95 \%$ confidence level (Table 1, column 5). First year students who had not been exposed to many technologies might have found the SMS puzzle much more interesting than the third year students. For third year students, the difficulty level of the content might have influenced their response to Q8. Nevertheless, it can be concluded that generally not much differences exists between the two groups with respect to the use of the SMS crossword puzzle for in-class learning.

We also performed a t-test to determine if all the scores were significantly above the mean score of 3 ( 3 represent the middle of the 5 points scale). Table 1 (last column) depicts the t-test statistic. Overall the results show that the motivational factors were in the same direction and significantly above the mean score of 3 .

\section{Discussion and limitations}

According to the students' comments, playing the SMS puzzle was "very cool", interesting, fun and provided a unique sense of motivation and competition. It was challenging because it required both lateral and longitudinal thinking to solve the puzzle. It was fun because the feedback was instantaneous and the game was unique.

One possible reason why the third year class found the SMS puzzle neither easy nor difficult to play could have been the difficulty level of the content. The clues and puzzle were easier for the first year than the third year puzzle. In the second evaluation, a longer SMS delay than for the first evaluation was also experienced. All these factors could have contributed to a slightly lower motivational score for the third year students as compared to the first year students.

The evaluation comes with some limitations. As suggested, the evaluation was intended to be a pilot thus the samples sizes were rather small. A small sample limits the strength of the findings and its conclusion. There is also the possibility of response bias, either in favor of or against the use of an SMS puzzle. Thus future evaluation will need to expand the size of the samples. Secondly, comparison between the two groups must take into consideration the fact that the crossword puzzles presented to the two groups were different. In future the experimental design may need to modify and present the same crossword to different groups and different crosswords to the same group. This would help identify the impact due to content and medium. Another approach would be to use a paper based crossword puzzle in comparison with an SMS crossword puzzle. Thirdly, the procedure for the evaluation should be documented and standardized. This would be to ensure that all the evaluations follow the same procedure and are completed within the allocated time frame. In reality not all students use a mobile phone; therefore groupings might need to be pre-arranged if the SMS crossword system were to be deployed. The current evaluation focuses on the aspect of motivation. Future evaluations could include the "fun" component of the SMS crossword system. While the operating cost of sending the SMS has been mentioned briefly, potential adopters must consider other costs such system development, training, and content development. 


\section{Conclusion}

In this paper an account has been provided of how a novel SMS crossword puzzle game was developed, and it was demonstrated that it can be deployed easily for in-class activity. It possesses motivational ability and is potentially capable of promoting learning. The evaluations showed a moderate (3.75 out of 5) motivational score can be achieved. In terms of motivation, there were no significant differences between the two groups who participated in the evaluation. Both groups indicated the desire to adopt the game.

However, a number of issues arose from the pilot evaluation. Firstly, the SMS crossword puzzle may not suit every segment of the student population. Therefore, in a class where the student population is diverse, it is recommended to neutralize such diversity through team work. Secondly, SMS latency can be an issue in deploying SMS for near real-time interactive activity such as games and voting. This is due to the fact that more traffic is channeled into the short message service center (SMSC) (CISCO, 2004, p.3). A distributed architecture rather than a centralized SMSC structure may be needed to resolve bottleneck issues. This requires cooperation with telecom providers. Alternatively, some normalization strategies may be required for using the technology in a class with a larger population. Thirdly, the motivational factors may diminish over time. This effect may need further investigation to determine the optimal frequency of use. While developed for teaching and learning, the SMS crossword puzzle can also be used as an icebreaker in corporate training sessions or even as a form of advertisement or for quiz nights.

\section{References}

Anderson, T. (2002). An updated and theoretical rationale for interaction. IT Forum. Retrieved 25 April 2004 from http://it.coe.uga.edu/itforum/paper63/paper63.htm

Bollen, L., Eimler, S., \& Hoppe, H., U. (2004). SMS-based discussions - Technology enhanced collaboration for a literature course. In 2nd IEEE International Workshop on Wireless and Mobile Technologies in Education (WMTE'04), 2004.

China SMS. (2006). A billion texts a day in China. Retrieved 14 December 2006, from http://www.smstextnews.com/2006/04/a billion texts.html

CISCO. (2004). A study in mobile messaging: The evolution of messaging in mobile networks, and how to efficiently and effectively manage the growing messaging traffic. Retrieved 14 August 14 2006, from http://www.cisco.com/en/US/netsol/ns341/ns396/ns177/networking_solutions_white_paper09186a008 $\underline{020 \mathrm{e} 2 \mathrm{a} 8 . \mathrm{shtml}}$

Clickatell. (2007). Bulk SMS. Retrieved 15 April 2007, from http://www.clickatell.com/solutions/business/bulksms.php

Derby. (2003). Derby College uses SMS tools from Cy-nap to improve student retention. Retrieved 1 September 2006, from http://www.cy-nap.com/press releases/derbyc.htm

Dempsey, J. V., Lucassen, B., Haynes, L. L., \& Casey, M. S. (1997). An exploratory study of forty computer games: COE technical report no. 97-2 (Technical Report): University of South Alabama.

Eggert, C. H., West, C. P., \& Thomas, K. G. (2004). Impact of an audience response system. Medical Education, $38,576$.

Galarneau, L. (2005). Authentic learning experiences through play: Games, simulations and the construction of knowledge. Retrieved 1 September 2006, from http://www.gamesconference.org/digra2005/viewabstract.php?id=18

Geek. (2006). Reliability of text message in New Zealand. Retrieved 14 August 2006, from http://www.geekzone.co.nz/forums.asp?ForumId=39\&TopicId=7769 
Howie, M. (2004). Setting the tone for new way to learn. Retrieved 1 September 2006, from http://news.scotsman.com/education.cfm?id=226532004

Houser, C., \& Thornton, P. (2004). Japanese college students' typing speed on mobile devices. In 2nd IEEE International Workshop on Wireless and Mobile Technologies in Education (WMTE'04), 2004.

Kearney, P. (2005). Cognitive callisthenics: Do FPS computer games enhance the player's cognitive abilities? Avaliable at http://www.digra.org/dl/db/06276.14516.pdf

Keller, J. M. (1987a). Development and use of the ARCS model of instructional design. Journal of Instructional Development, 10 (3), 2-10.

Keller, J. M. (1987b). Strategies for stimulating the motivation to learn. Performance and Instruction Journal, $26(8), 1-7$.

Keller, J. M. (1987c). The systematic approach of motivational design. Performance and Instruction Journal, $26(9 / 10), 1-8$.

Lian, Y. (2003). Adaptive teaching for large classes. International Conference on Engineering Education. July 21-25, 2003, Valencia, Spain.

Markett, C., Sánchez, I. A., Weber, S., \& Tangney, B. (2006). Using short message service to encourage interactivity in the classroom. Computer Education, 46(3), 280-293.

Medina, E. (2005). Digital games: A motivational perspective. Available at http://www.digra.org/d1/db/06276.30561.pdf

OSU (2006). Committee on classroom response systems. Retrieved 15 August 2006, from http://telr.osu.edu/clickers/about/crs_final_report.pdf

Prensky, M. (2002). The motivation of gameplay or the real 21st century learning revolution. On the Horizon, $10(1)$.

Prensky, M. (2003). Digital game-based learning. ACM Computers in Entertainment, 1(1).

Purdue (2006). Purdue's system-wide technology lets students click in to academics. Retrieved 15 August 2006, from, http://www.itap.purdue.edu/newsroom/news.cfm?NewsID=497

Song, S. H. \& Keller, J. M. (2001). Effectiveness of motivationally adaptive computer-assisted instruction on the dynamic aspects of motivation. Educational Technology, Research and Development, 49 (2), 522.

Stone, A., Briggs, J., \& Smith, C. (2002). SMS and interactivity - Some results from the field, and its implications on effective uses of mobile technologies in education. Proceedings of the IEEE International Workshop on Wireless and Mobile Technologies in Education, 2002, Växjö, Sweden 147-151

Tung, L. L. (2004). Service quality and perceived value's impact on satisfaction, intention and usage of short message service (SMS). Information Systems Frontiers 6, (4), 353-368.

Wlodkowski, R. J. (1999). Enhancing adult motivation to learn (2nd ed). San Francisco: Josey-Bass. 


\section{Biographies}

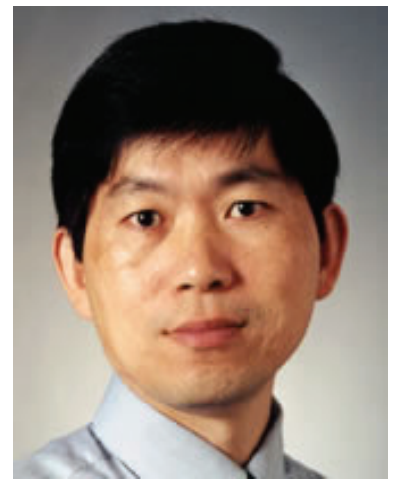

Dr. Tiong T. Goh is currently with the School of Information Management at Victoria University of Wellington, New Zealand. His research areas include mobile learning, mobile games for education and mobile database applications and development.

http://www.sim.vuw.ac.nz/staff/tiong-goh.aspx

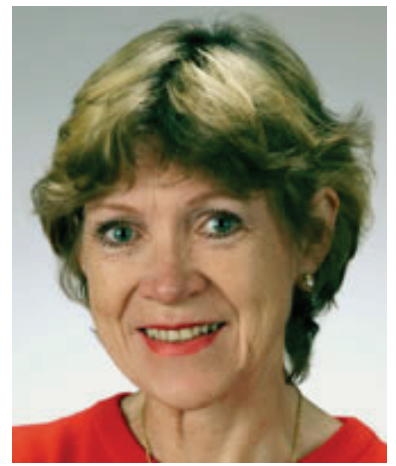

Val Hooper has been lecturing for nearly two decades in diverse areas including Information Systems Management; Electronic commerce; Brand Management; Economics; Strategic Management; Marketing Management; and Research Methodology. In 2004 she was awarded the Victoria University of Wellington Teaching Excellence Award. She has also practiced widely as a management and specialist consultant with clients emanating from a range of industries including industrial engineering, agricultural engineering, a university consortium, a national health research council, and the tobacco industry.

Val obtained her PhD in Information Systems from Victoria University, and her current research focuses on the strategic alignment between IS and marketing, and the impact of that alignment on marketing performance and business performance. Further research interests include all areas pertaining to the strategic application of IS to business performance, to e-commerce, and to $\mathrm{m}$-commerce; as well as the application of IS in tertiary education. 